\title{
Safety Analysis of Hydrogen Vehicles and Infrastructure
}

T. Jordan, W. Breitung

This document appeared in

Detlef Stolten, Thomas Grube (Eds.):

18th World Hydrogen Energy Conference 2010 - WHEC 2010

Parallel Sessions Book 5: Strategic Analyses / Safety Issues / Existing and Emerging Markets

Proceedings of the WHEC, May 16.-21. 2010, Essen

Schriften des Forschungszentrums Jülich / Energy \& Environment, Vol. 78-5

Institute of Energy Research - Fuel Cells (IEF-3)

Forschungszentrum Jülich $\mathrm{GmbH}$, Zentralbibliothek, Verlag, 2010

ISBN: 978-3-89336-655-2 


\title{
Safety Analysis of Hydrogen Vehicles and Infrastructure
}

\author{
Thomas Jordan and Wolfgang Breitung
}

\begin{abstract}
This chapter summarizes the state-of-the-art related to safety analysis of hydrogen vehicles and infrastructure. Many aspects have been treated in more detail in the reports of the European Commission-supported HySafe Network (www.hysafe.net). The potential use of hydrogen as an energy carrier and in particular its application as a fuel in vehicles require new operational parameters which are very different from those currently used in the chemical and petrochemical industries. This is why the industrial experience gained so far is applicable only partially. Safety analyses require the definition of acceptable risk levels, which are implicitly or explicitly contained in standards or regulations or might be derived from established technologies. A quantitative measure of risk is the product of a probabilistic factor representing the frequency of occurrence of hazardous events and of the associated damage. As these frequencies of failures are largely unknown and difficult to predict, it is recommended to focus on the deterministic evaluation of the damage and of the effectiveness of mitigation measures. For the deterministic consequences, evaluation of the distribution, ignition, and combustion phenomena are the key elements of the event sequence. The distribution of hydrogen is well understood as long as phase transition or near-critical conditions might be excluded. The latter phenomena are linked mainly to liquid hydrogen applications. The knowledge and modeling capabilities regarding the ignition phenomena are still incomplete. The classification of ignition sources into weak and strong igniters and the degree of conservatism related to assumptions about timing and location are still under development. Transitional behavior of flames plays an important role. The principal mechanisms are well captured, but the transfer to real accidental scenarios and the new physical domains is not yet accomplished. Commonly agreed, harmonized performancebased standardization on an international level relies on an appropriate understanding of the relevant mechanisms. This understanding will be further developed by internationally coordinated pre-normative research.
\end{abstract}

\section{Copyright}

Stolten, D. (Ed.): Hydrogen and Fuel Cells - Fundamentals, Technologies and Applications. Chapter 31. 2010. Copyright Wiley-VCH Verlag GmbH \& Co. KGaA. Reproduced with permission. 